\title{
A Pathfinder-Based Safe Evacuation Model for Ultradeep Underground Public Space
}

\author{
Lili Dong ${ }^{1}$, Jin $\mathrm{Wu}^{2}$, Wei Wang ${ }^{3 *}$, Wangshe $\mathrm{Hu}^{1}$ \\ ${ }^{1}$ School of Architecture and Urban Planning, Chongqing Jiaotong University, Chongqing 400074, China \\ ${ }^{2}$ CCTEG Chongqing Engineering (Group) Co., Ltd., Chongqing 400010, China \\ ${ }^{3}$ School of Art, Design and Architecture, University of Huddersfield, HD1 3DH, West Yorkshire, United Kingdom
}

Corresponding Author Email: wei.wang2@hud.ac.uk

https://doi.org/10.18280/ijsse.100406

Received: 15 March 2020

Accepted: 9 June 2020

\section{Keywords:}

safe evacuation model, ultradeep underground public space (UUPS), sunken shelter, safe evacuation system (SES)

\begin{abstract}
In recent years, many cities have stepped up the development and use of underground public space. However, the development of underground space is constrained by safe evacuation. It is urgent to design a suitable safe evacuation model for ultradeep underground public space (UUPS). From the perspective of building design, this paper creates a novel safe evacuation model that integrates sunken shelter with a self-designed safe evacuation system (SES), and compares its effect with that of other models. Then, the application of our model in Hongtudi Station, Line 10 of Chongqing Rail Transit (CRT) was simulated on Pathfinder. The results show that the safe evacuation model, which couples sunken shelter with the SES, is feasible to evacuate personnel from the UUPS. The research sheds new light on the safe evacuation technique from the UUPS.
\end{abstract}

\section{INTRODUCTION}

In recent years, urbanization picks up speed around the world, and the environmental requirements become increasingly strict. Under these constraints, the rational development and use of urban underground space have morphed into the primary land-saving strategy, providing a sustainable development model for future cities [1, 2].

For various reasons, the safe evacuation from underground space must be assured before effectively developing and using the space in urban areas: Firstly, there are various problems with underground space development, due to the lack of pertinent design codes on safe evacuation or mature acceptance procedures for fire protection; Besides, the limited number of emergency exits and escape routes [3] in underground buildings restricts the evacuation efficiency in case of fire, and the bottom-up escape direction adds to the difficulty of evacuation; Furthermore, the smoke also spreads from bottom to the top, making the fire even more dangerous.

The research into the safe evacuation of personnel can be traced back to late 1970s. The recent studies in this field have focused on simulation [4-12]. For instance, Haghani [13] summed up three main optimization methods to improve evacuation efficiency: building design and infrastructure adjustment; mathematical programming and optimization of route/departure time plan; behavior modification, training, and active guidance. Alam and Habib [14] identified the most likely collision hotspots by the Bayesian theory, and encodes them with the micro simulation model of collision occurrence module in dynamic traffic, revealing that collision has a serious impact on evacuation. Facing the overlong and complex evacuation routes in large underground public space, Gao et al. [15] introduced a constraint-based design model to automatically optimize the location of evacuation gates in buildings; Under space constraint and design constraint, the introduced model shortens the evacuation time by minimizing the length of the evacuation route. $\mathrm{Li}$ and $\mathrm{Xu}$ [16] proposed a safe evacuation model for confined space, which considers the differences in individual features and building factors.

Drawing on the above studies, this paper mainly designs a safe evacuation model for ultradeep underground public space (UUPS), and implements the model in an actual UUPS in a systematic and complete manner.

\section{SAFE EVACUATION MODEL}

Currently, the evacuation model for underground public space is the same as that for surface buildings. The model consists of three parts: horizontal evacuation, vertical evacuation, and exit evacuation. Considering the uniqueness and complexity of the UUPS, this paper compares multiple evacuation models through simulation, according to relevant laws and regulations on building design. Through the comparison, the features of each model were identified, and a safe evacuation model that suits different burial depths and environments was designed. Then, the evacuation efficiency of the designed model was compared with that of other models under the same simulation scenario.

\subsection{Staircase evacuation model}

The most common evacuation model for the UUPS is to evacuate by staircase. In general, the parameters of a staircase in public space are as follows: the minimum clear width of a flight is $1.40 \mathrm{~m}$, the minimum step width is $280 \mathrm{~mm}$, and the maximum step height is $160 \mathrm{~mm}$.

It is assumed that the underground space has two straight evacuation staircases, which are arranged parallel to each other in the same direction. For simplicity, the two staircases are collectively referred to as parallel staircases. Suppose 100 personnel, who are randomly distributed underground, need to 
be evacuated from a $20 \mathrm{~m} \times 20 \mathrm{~m}$ area in the underground space. The evacuation speed was set to $1.19 \mathrm{~m} / \mathrm{s}$ and kept constant throughout the evacuation. On this basis, the evacuation time for the said personnel by the parallel staircases was simulated on Pathfinder (Figure 1) at different burial depths.

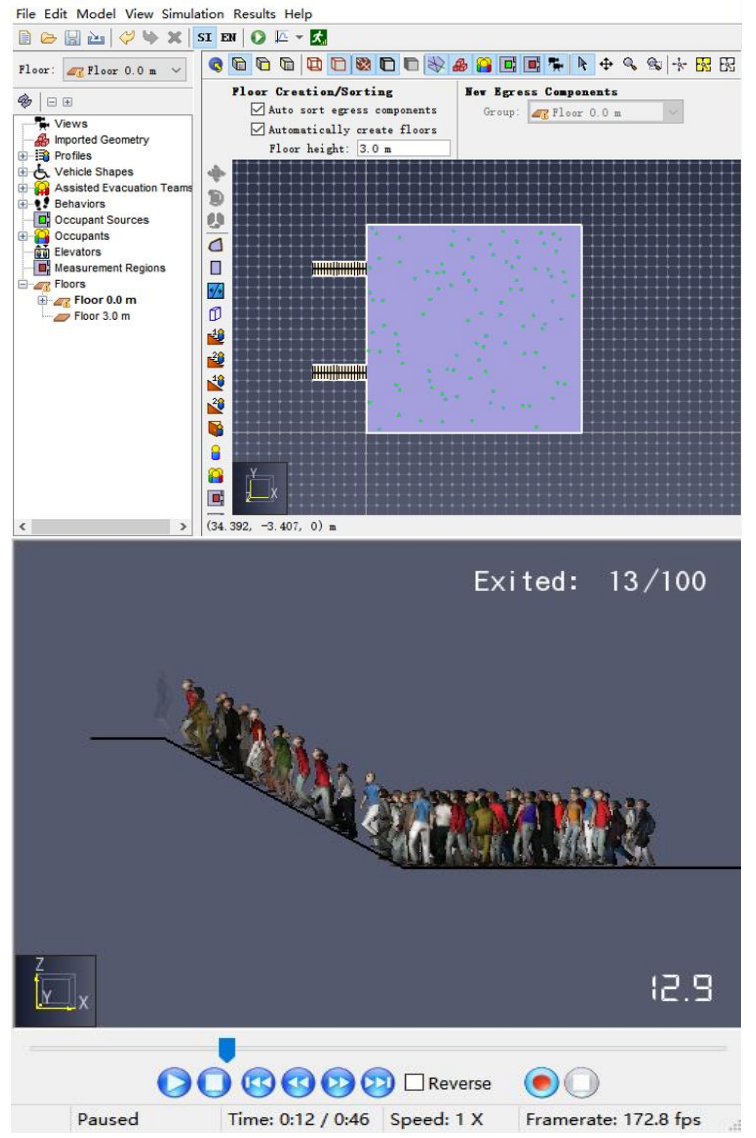

Figure 1. The simulation scenario and procedure of parallel staircases

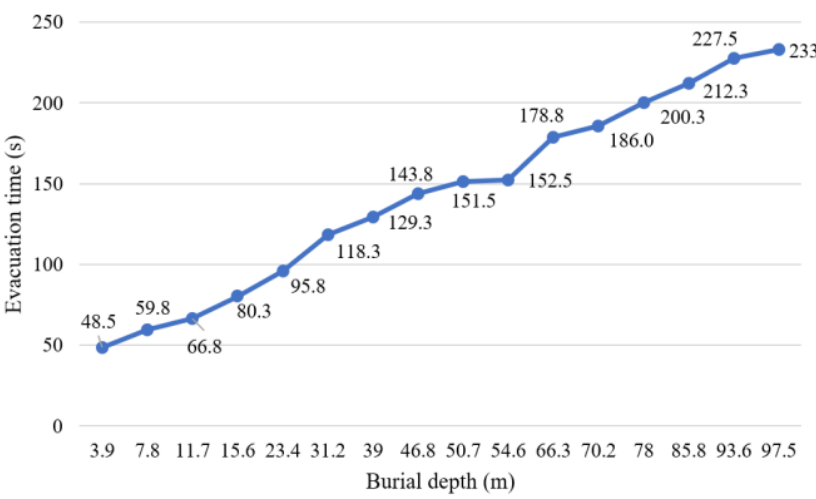

Figure 2. The evacuation time by parallel staircases at different burial depths

According to the results of Pathfinder simulation (Figure 2), when the evacuation speed and other conditions remained the same, the evacuation time is positively correlated with the burial depth: the greater the depth, the longer the evacuation time.

In addition, the evacuation time could be affected by the staircase deployment. Hence, the two staircases were redeployed in opposite directions, without changing any staircase parameters. In this case, the two staircases are collectively referred to as opposite staircases. Then, the evacuation time by opposite staircases was simulated on Pathfinder (Figures 3 and 4). The evacuation time by opposite staircases at different burial depths is recorded in Figure 5.

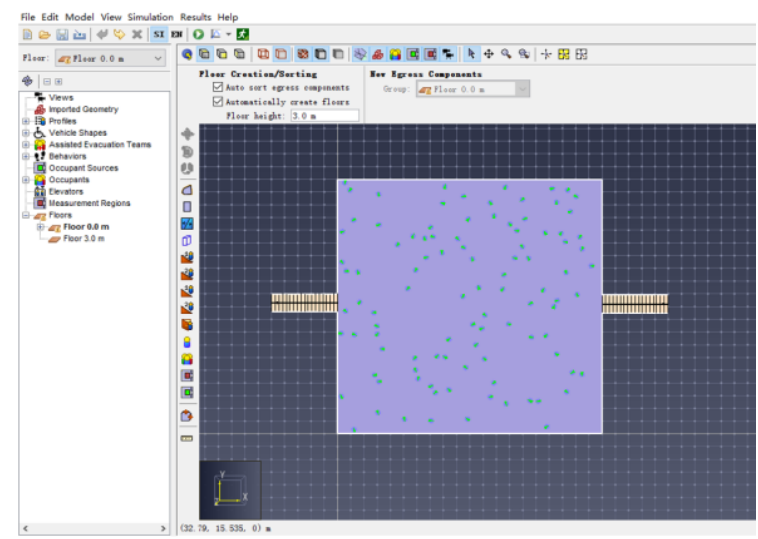

Figure 3. The simulation scenario of opposite staircases
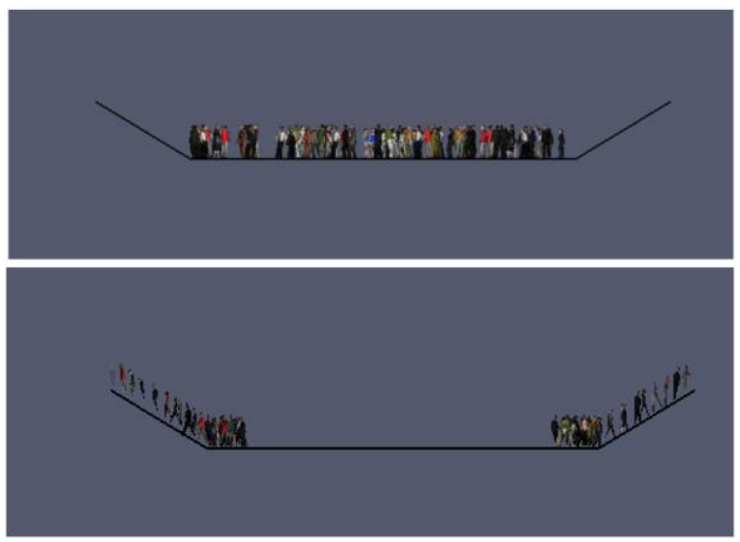

Figure 4. The simulation procedure of opposite staircases

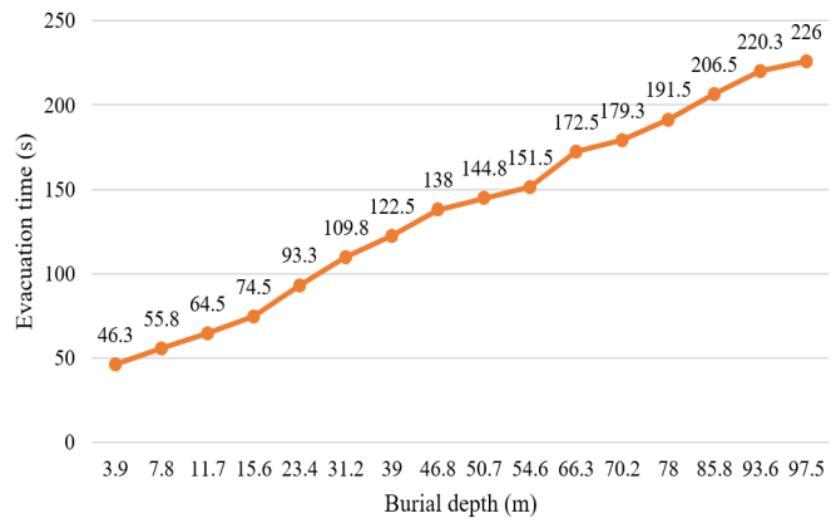

Figure 5. The evacuation time by opposite staircases

As shown in Figure 5, the evacuation time by opposite staircases is also positively correlated with the burial depth. Of course, the two staircase deployments offer different evacuation routes (Figure 6), resulting in varied evacuation effects.

In parallel staircases, the two staircases are arranged in the same direction. Thus, the crowd is evacuated in the same direction, avoiding the collision induced by multi-direction evacuation. By contrast, in opposite staircases, the two staircases are arranged in opposite directions. The crowd is evacuated in two different directions, reducing the probability of congestion in the same direction. 


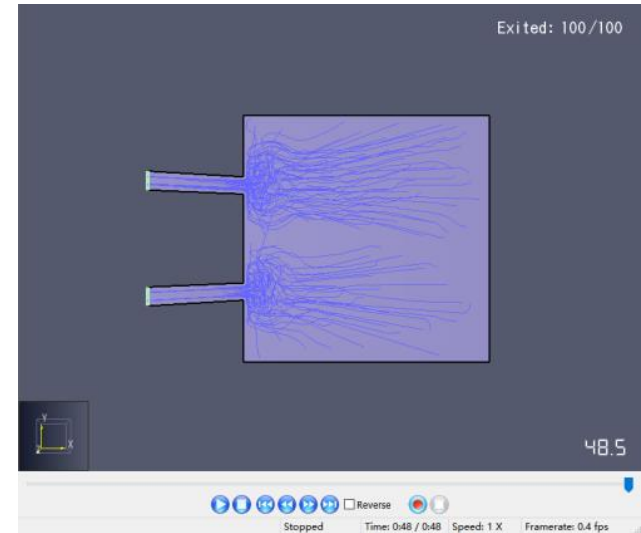

(a) Parallel staircases

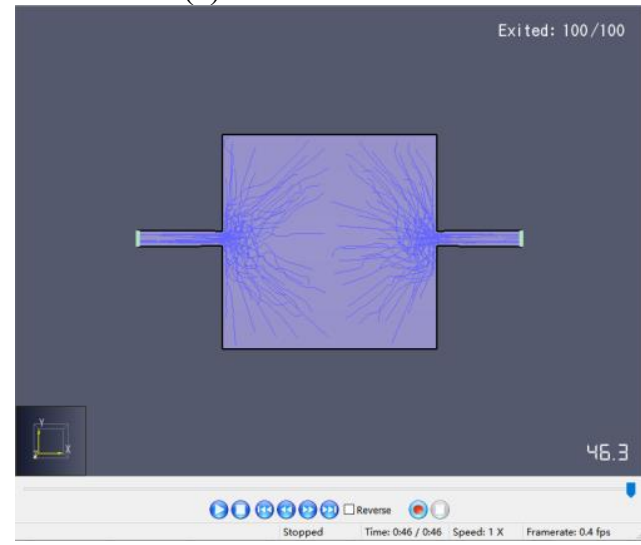

(b) Opposite staircases

Figure 6. The evacuation routes of two staircase deployments

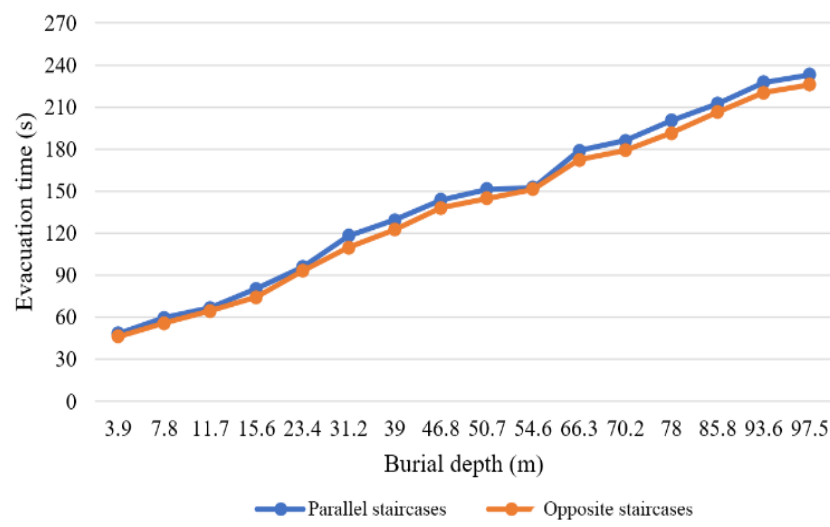

Figure 7. The comparison of evacuation effects between the two staircase deployments

Figure 7 compares the evacuation effects of the two staircase deployments. It can be intuitively learned that the evacuation time by opposite staircases was slightly shorter than that by parallel staircases. In the ideal state, however, the evacuation by opposite staircases is on average $4.2 \%$ faster than by parallel staircases. The two staircase deployments had similar evacuation efficiencies at the burial depth of 54.6m. At any other depth, the evacuation by opposite staircases was always more efficient than that by parallel staircases. The efficiency gap was sometimes as large as $7.2 \%$. To improve evacuation efficiency and reduce evacuation time, it is recommended to arrange the staircases in the UUPS in opposite directions.

\subsection{Staircase + escalator evacuation model}

In the UUPS, escalators are the most frequently used means of transportation. In emergency situations, the personnel are used to return by the way they came to the space, which increases the chance of using escalators during evacuation. Therefore, it is meaningful to simulate the evacuation by escalator before identifying the most suitable evacuation model.

In the simulation scene of staircase evacuation model, two escalators were deployed with a clear width of $1.0 \mathrm{~m}$. The inclination angle of the escalators was controlled within $30^{\circ}$, and the running speed was set to $0.65 \mathrm{~m} / \mathrm{s}$. It is assumed that the escalators can operate normally and the crowd is evacuated at the constant speed of $1.19 \mathrm{~m} / \mathrm{s}$, in the event of an emergency. Then, the evacuation time by escalator at different burial depths was simulated on Pathfinder.

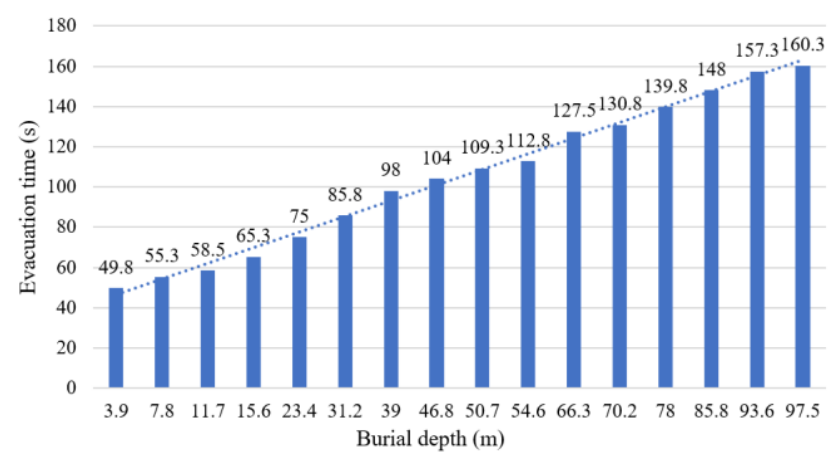

Figure 8. The evacuation time by escalator at different burial depths

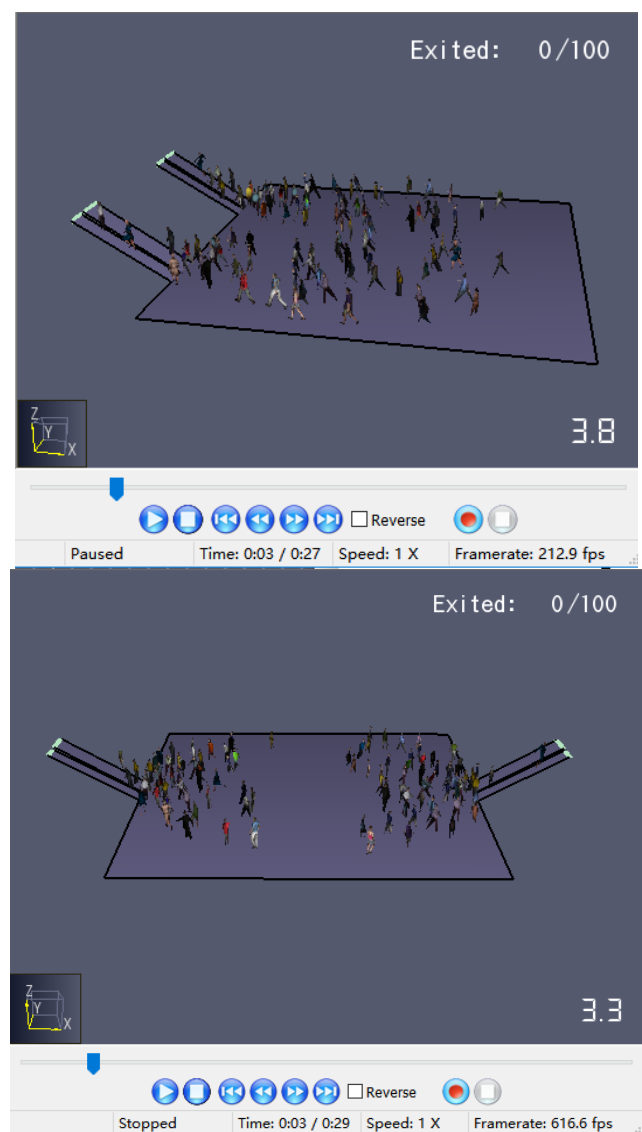

Figure 9. The simulation procedure of staircase + escalator evacuation model 


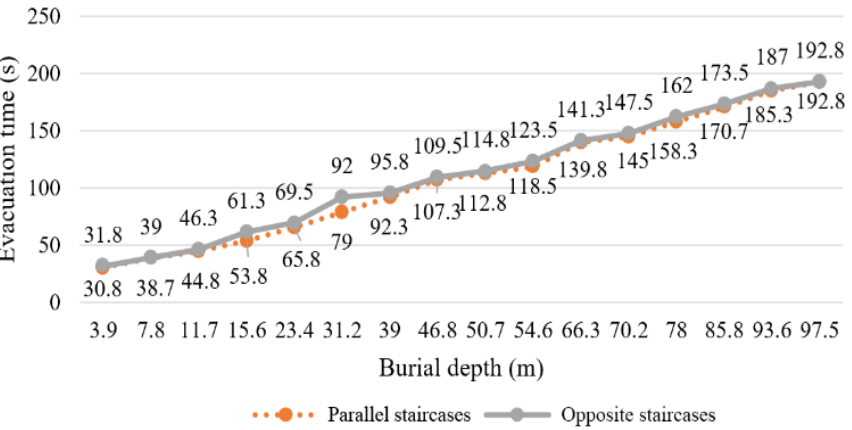

Figure 10. The comparison of evacuation effects between the two staircase + escalator evacuation models

Comparing the evacuation time by escalator (Figure 8) with that by staircase, the staircase evacuation model was more efficient than the escalator evacuation model, when the burial depth was smaller than $7.8 \mathrm{~m}$ (i.e. the height of two stories); in this case, the personnel should be evacuated by staircase. With the growing burial depth, the escalators had an edge in evacuation over staircases, leading to a relatively short evacuation time. In normal situation, it is more efficient to evacuate personnel from the UUPS by escalator than by staircase. If both staircases and escalators are used to evacuate personnel from the UUPS, there is a great chance that the evacuation will be more efficient and less time-consuming. Under the same simulation scenario, two staircases and two escalators were deployed in the UUPS, without changing any of their parameters. Then, a Pathfinder simulation (Figure 9) was conducted to obtain the evacuation time by staircase + escalator at different burial depths.

Comparing the evacuation time by staircase + escalator (Figure 10) with that by staircase or escalator alone, the staircase + escalator evacuation model is much more efficient than the staircase evacuation model and the escalator evacuation model. The combination of parallel staircases and escalators (parallel staircases + escalator) consumed basically the same time as the combination of opposite staircases and escalator (opposite staircases + escalator), with large fluctuations in very few burial depths.

Contrary to the results between parallel staircases and opposite staircases, the parallel staircases + escalator model consumed slightly shorter time than the opposite staircases + escalator model. The relatively large differences in evacuation time at $15.6 \mathrm{~m}$ and $31.2 \mathrm{~m}$ are the result of the fact that some personnel lingered between opposite staircases, which increase the evacuation distance and pushes up the evacuation time. In ideal state, the parallel staircases + escalator model was $3.6 \%$ more efficient than the opposite staircases + escalator. To minimize the evacuation time from the UUPS, the two staircase + escalator evacuation models should be optimized based on the actual burial depth.

\subsection{Elevator evacuation model}

The UUPS is generally buried deeper than $50 \mathrm{~m}$. If the personnel are evacuated by staircases, the physical exhaustion will be a nonnegligible factor. Previous research has shown that the climbing speed of human will decrease by $8 \%-12 \%$ after ascending four stories. Hence, the mean evacuation speed of the crowd by staircase will slow down by $10 \%$ for every $3.9 \mathrm{~m}$ (i.e. the height of one story) from the burial depth of $15.6 \mathrm{~m}$. As a result, elevator evacuation is an efficient model for evacuation from the UUPS.

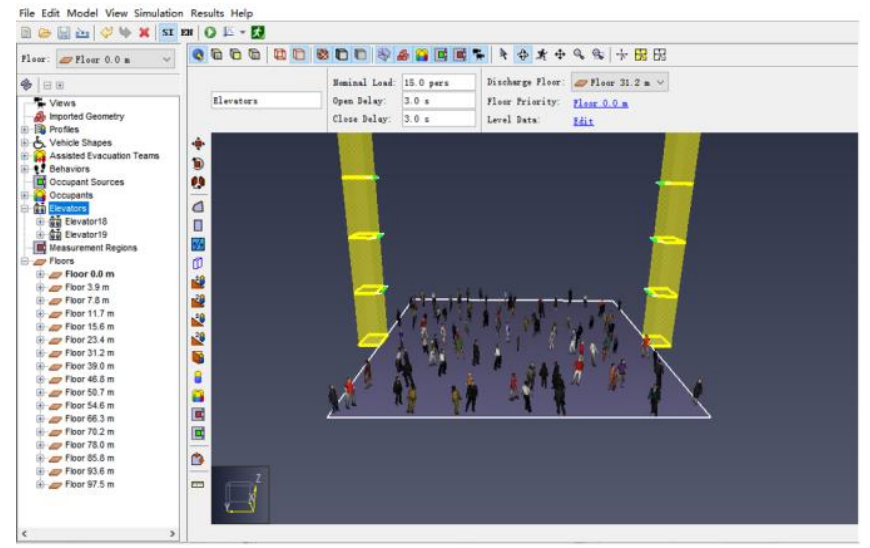

Figure 11. The simulation procedure of elevator evacuation model

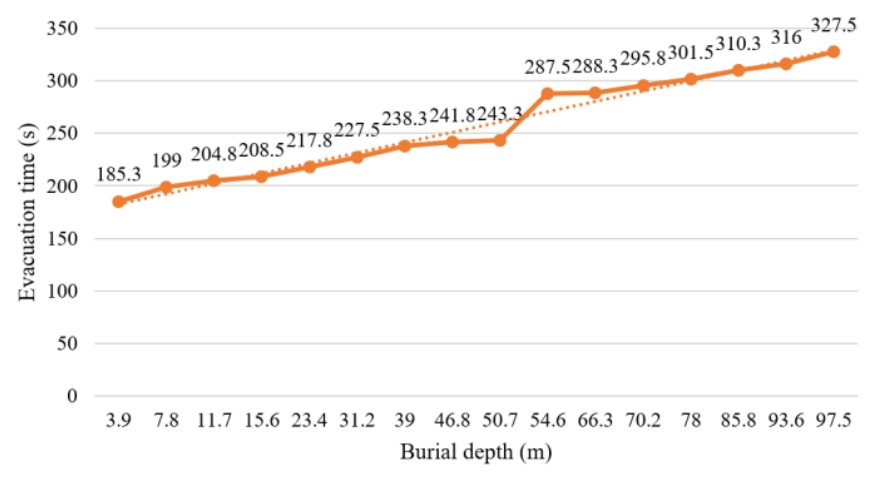

Figure 12. The evacuation time by elevator at different burial depths

Under the same simulation scenario, two elevators were deployed to evacuate personnel from the UUPS. As per the relevant regulations, an evacuation elevator should have a load capacity no less than 1.3 ton, a speed of no less than $5 \mathrm{~m} / \mathrm{s}$, and a carriage no smaller than $1 \mathrm{~m} \times 1.5 \mathrm{~m}$. For the two elevators, the relevant parameters were configured as follows: the maximum speed is $8 \mathrm{~m} / \mathrm{s}$, the acceleration is $1.2 \mathrm{~m} / \mathrm{s}^{2}$, the total time for opening and closing the door is $7 \mathrm{~s}$, the door width is $1.2 \mathrm{~m}$, the carriage size is $2 \mathrm{~m} \times 1.5 \mathrm{~m}$, and the maximum number of riders is 15 (Figure 11). It is assumed that the personnel to be evacuated are randomly distributed at various locations in the underground space, and will be evacuated at a constant horizontal speed of $1.19 \mathrm{~m} / \mathrm{s}$. On this basis, a Pathfinder simulation was performed to obtain the evacuation time by elevator at different burial depths.

The simulation results (Figure 12) show that, when the burial depth is shallow, elevator evacuation model consumed more time than staircase evacuation model and escalator evacuation model. There are two reasons for the relatively long evacuation time: On the other hand, each elevator needs to move back and forth, doubling the travel distance; on the other hand, a lot of time is consumed by the opening and closing of elevator doors and the entry and exit of personnel. As the burial depth went deeper, the evacuation efficiency by elevators continued to increase.

Of course, it is unwise to solely rely on elevators for evacuation. If so, many personnel will be stranded before the elevators, passively waiting for rescue. In actual evacuation scenes, elevators, escalators, and staircases should be combined to facilitate personnel evacuation from the UUPS. 
2.4 Sunken shelter + safe evacuation system (SES) evacuation model

\subsubsection{Definition of the SES}

In the UUPS, the staircase evacuation model takes a long time and faces the problem of physical exhaustion. The mean upward speed of staircase evacuation is merely $0.5 \mathrm{~m} / \mathrm{s}$. In normal conditions, the mean upward speed of elevators is as fast as $2.5 \mathrm{~m} / \mathrm{s}$ [17].

Therefore, this paper designs a vertical evacuation system called the SES, drawing on the principle of escape shafts, and the evacuation method for super high rises (the personnel are evacuated vertically by staircase and elevator to emergency exits directly leading to the outdoors).

As shown in Figure 13, the proposed SES consists of both elevators and smoke-proof staircases $[18,19]$. To ensure the operability and safety of the elevators, the SES must meet three requirements: the elevators should satisfy the fire protection standards, multi-circuit power supplies should be in place, and a fire front room should be available.
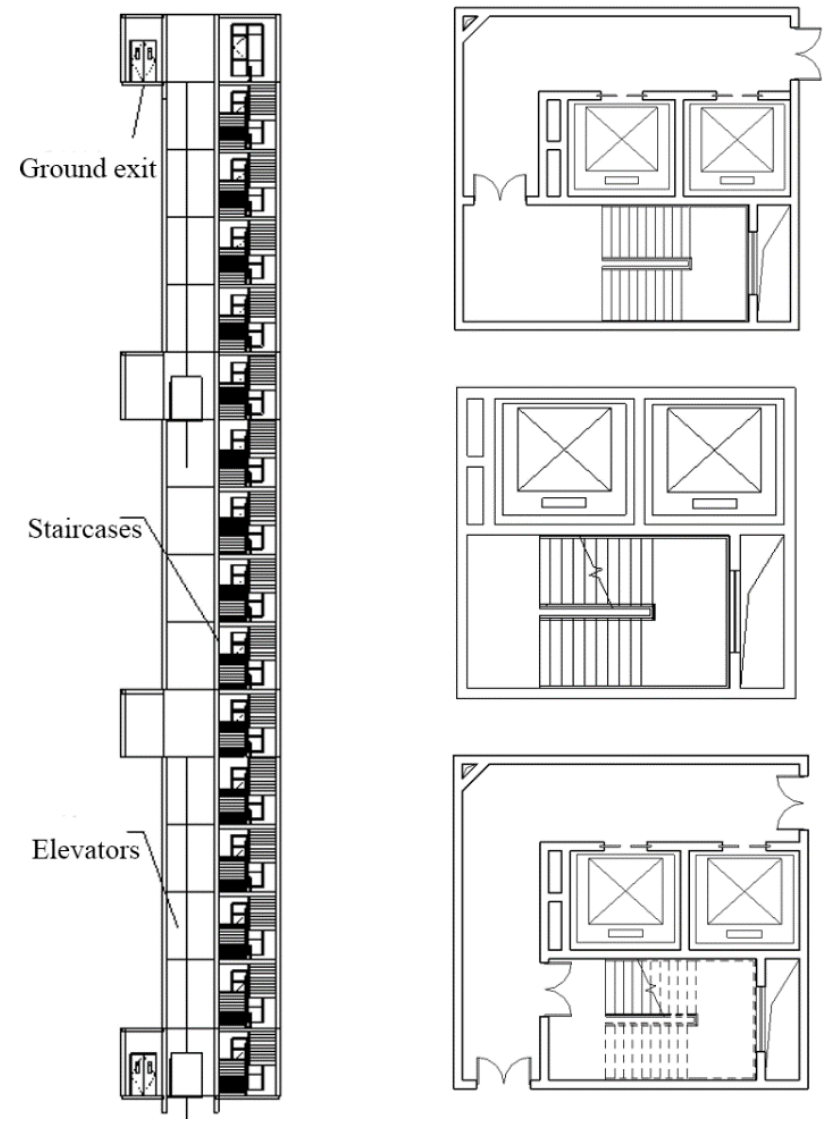

Figure 13. The profile of the SES in plan

\subsubsection{Safe evacuation model}

If the underground space is large or ultra-deep, the personnel can also be evacuated to a safe space called the shelter [20]. In the UUPS, vertical evacuation channels like staircase or slides were set up at a certain interval to connect the public space with the sunken shelter. To prevent smoke propagation in the shelter, reverse pressurized air supply was introduced as an isolation measure between the shelter and the evacuation channels. Together, the vertical evacuation channels and the horizontal evacuation channel serve as antismoke front rooms. Meanwhile, the SES was separated from the underground public space, to prevent the system from being affected by fire or even explosion. Finally, the sunken shelter was connected to the SES by the horizontal evacuation channel, forming a complete safe evacuation model (Figure 14).

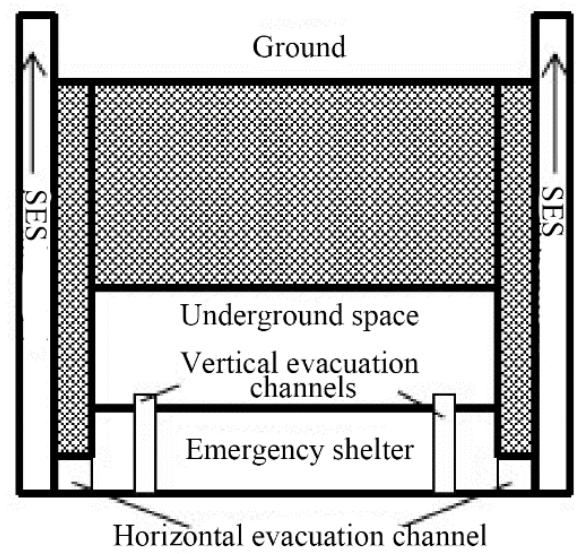

Figure 14. The sketch map of the sunken shelter + SES evacuation model

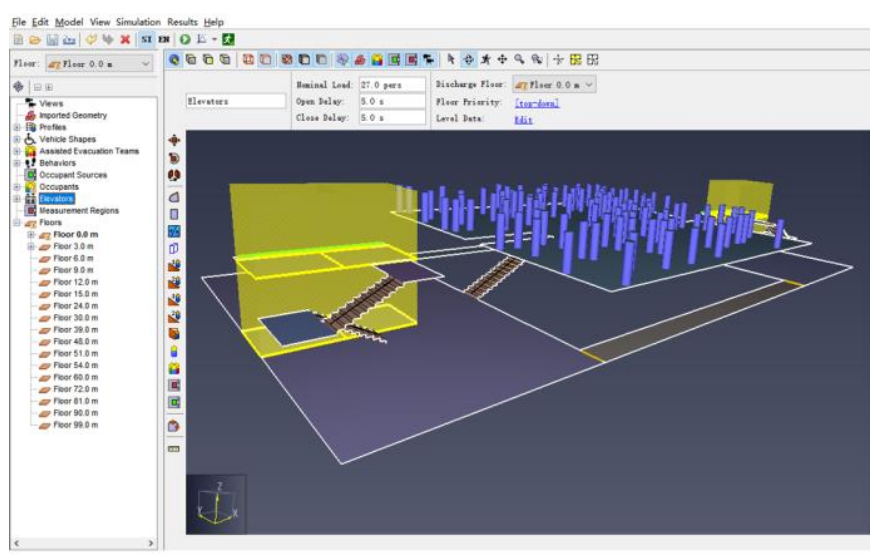

Figure 15. The scenario of evacuation by sunken shelter + SES

Next, the evacuation by sunken shelter + SES was simulated on Pathfinder (Figure 15) under the following conditions: 100 personnel, who are randomly distributed underground, need to be evacuated from a $20 \mathrm{~m} \times 20 \mathrm{~m}$ area in the underground space; the evacuation speed remains constant at $1.19 \mathrm{~m} / \mathrm{s}$; the sunken shelter is deployed beneath the layer to be evacuated; the two layers are connected with straight staircases (clear width: $1.40 \mathrm{~m}$ ); each shelter is connected to an SES via safety channels; every SES has two elevators and two staircases; for each elevator, the rated number of riders is 21 , the maximum speed is $8 \mathrm{~m} / \mathrm{s}$, the acceleration is $1.2 \mathrm{~m} / \mathrm{s}^{2}$, the total time for opening and closing the door is $7 \mathrm{~s}$, the door width is $1.5 \mathrm{~m}$, and the carriage size is $2.5 \mathrm{~m} \times 2.5 \mathrm{~m}$; for the staircases, the clear width is $1.50 \mathrm{~m}$, and the landing width is $1.50 \mathrm{~m}$.

During the evacuation by sunken shelter + SES, the personnel prefer to escape by elevators. Thus, some personnel would linger between the two elevators, rather than choose the staircases, even if the elevators are fully loaded. For this reason, the evacuation by elevator and evacuation by staircase in the SES were separately simulated on Pathfinder.

According to the simulated results (Figure 16), the evacuation time curve of staircase evacuation model was steeper than that of elevator evacuation model, indicating that, 
in ideal state, it is far more efficient to evacuate the personnel by elevator than by staircase in the SES. If only elevators were adopted, the evacuation time increased slowly with the growing burial depth. However, the staircase evacuation model achieved better effect in the SES, when the burial depth was smaller than $15.6 \mathrm{~m}$ (the height of four stories); once the depth surpassed $15.6 \mathrm{~m}$, the elevator evacuation model became more efficient. Therefore, the most efficient model should be chosen depending on the burial depth of the target project.

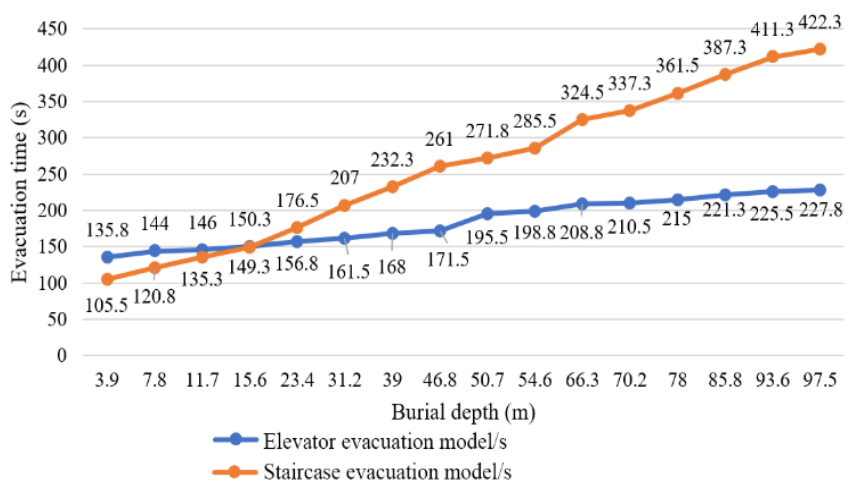

Figure 16. The evacuation time of the sunken shelter + SES evacuation model at different burial depths

\section{CASE ANALYSIS}

\subsection{Project overview}

Located under Wuhong Road, Hontudi Station of Line 10 of Chongqing Rail Transit (CRT) is a north-south metro station beneath the station of the same name of CRT Line 6 . The two stations constitute a cross-shape interchange station. The $11,188.8 \mathrm{~m}^{2}$ station hall of Line 10 is $222 \mathrm{~m}$ from north to south, and buried at the depth of $94.467 \mathrm{~m}$. The burial depth is equivalent to the height of 31 stories, and 4.7 times the depth of standard bomb shelter $(20 \mathrm{~m})$. The hall is the deepest UUPS among all metro stations in China. Therefore, the safe evacuation from the station can provide a good reference for the development and use of the UUPS.

\subsection{Simulation and analysis of evacuation time}

To solve the personnel evacuation problem of the target station, a sunken shelter was deployed beneath the layer to be evacuated, and connected to the latter layer with straight staircases (clear width: $1.40 \mathrm{~m}$ ); each shelter is connected to an SES via safety channels.

A total of five SESs were arranged in the station. In each SES, there are two elevators (rated number of riders: 21 ) and two staircases (clear width: $1.40 \mathrm{~m}$; landing width: $1.50 \mathrm{~m}$ ). For each elevator, the maximum speed is $8 \mathrm{~m} / \mathrm{s}$, the acceleration is $1.2 \mathrm{~m} / \mathrm{s}^{2}$, the total time for opening and closing the door is $7 \mathrm{~s}$, the door width is $1.5 \mathrm{~m}$, and the carriage size is $3 \mathrm{~m} \times 3 \mathrm{~m}$.

It is assumed that 700 personnel, who are randomly distributed in the hall and platform, need to be evacuated (Figure 17), and the evacuation speed remains constant at $1.19 \mathrm{~m} / \mathrm{s}$. The simulation scenario of the sunken shelter + SES evacuation model is shown in Figure 18. The simulation scenarios of the staircase evacuation model and elevator evacuation model in the SES are displayed in Figures 19 and 20 , respectively.

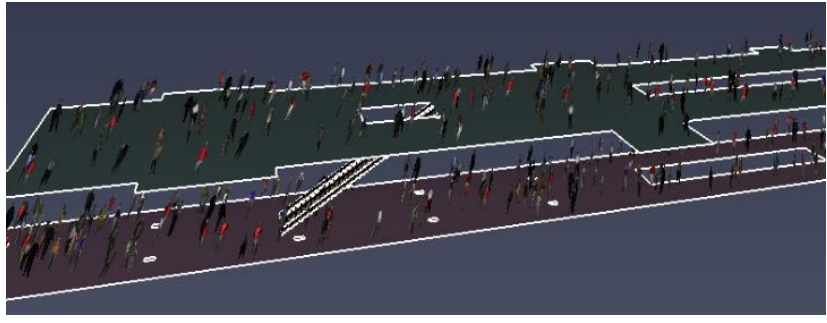

Figure 17. The simulation scenario of the metro station

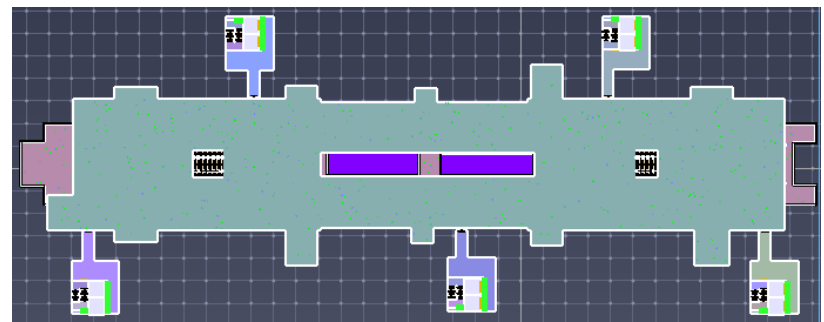

Figure 18. The simulation scenario of the sunken shelter + SES evacuation model

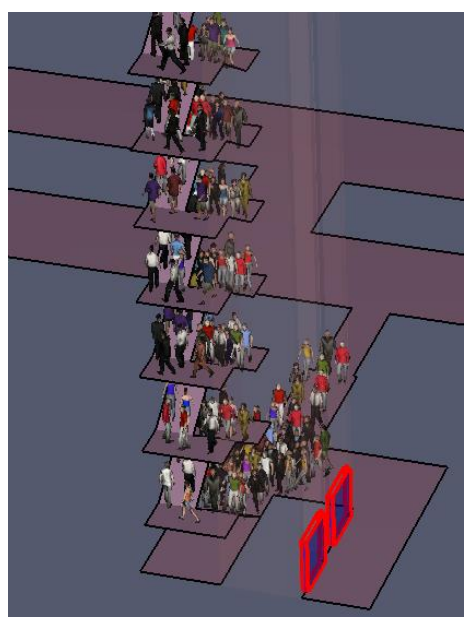

Figure 19. The simulation scenario of the staircase evacuation model

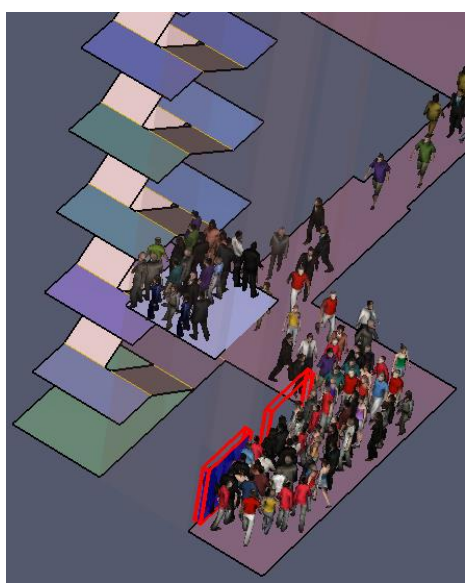

Figure 20. The simulation scenario of the elevator evacuation model

When a fire broke out in the hall, the simulation shows that all personnel could be evacuated to the platform in $89.5 \mathrm{~s}$. With only two staircases and escalators in the station, the personnel are very likely to throng at the staircases. Figure 21 illustrates 
the evacuation route for personnel on the platform.

If all personnel are evacuated only through the staircases in SES, in the ideal state, the sunken shelter + SES evacuation model costed an average of $278.8 \mathrm{~s}$ to evacuate the first person to the ground, and $602.5 \mathrm{~s}$ to evacuate the last person to the ground.

Figure 22 shows the passing rate of the exits in staircase evacuation model. It can be seen that the evacuation had good continuity when all personnel were evacuated by staircase. From 330 s to 540 s, the passing rates slightly fluctuated between 0.5 and 0.6 persons $/ \mathrm{s}$, indicating that the personnel continued to pass through the exits. From 540s to the end of evacuation, almost all personnel were evacuated through the exits. But there were still personnel passing through one of the exits, causing a hike in passing rate to 0.95 persons $/ \mathrm{s}$.

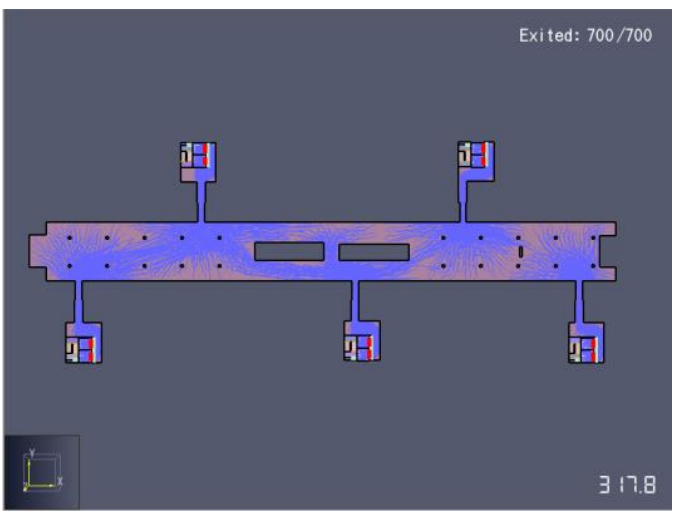

Figure 21. The evacuation route from the platform

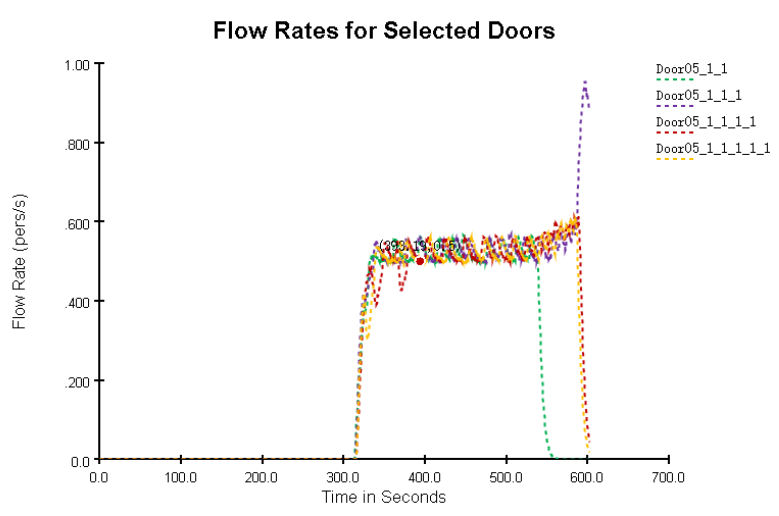

Figure 22. The passing rates of the exits in staircase evacuation model

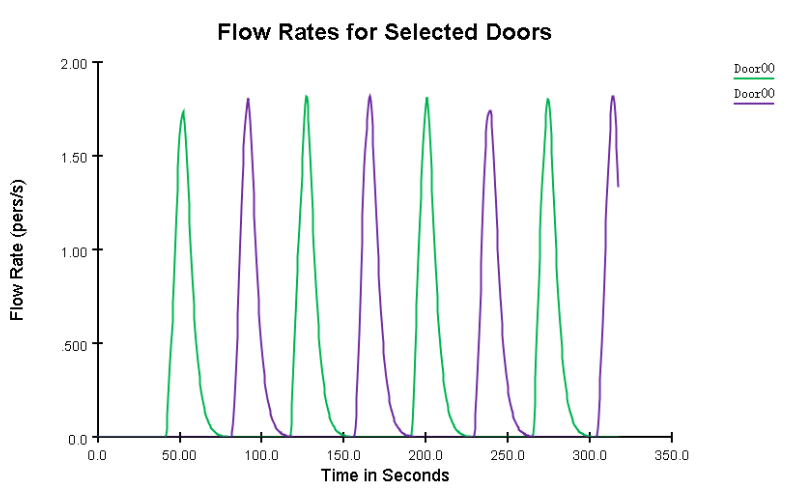

Figure 23. The passing rates of the exits in elevator evacuation model
Then, the parameter settings in Pathfinder were adjusted to simulate the evacuation of personnel only by elevators in the SES in the event of a fire. The results show that all personnel could be evacuated in 317.8 s by the sunken shelter + SES evacuation model. Figure 23 provides the passing rates of the exits in elevator evacuation model. It can be seen that the passing rates fluctuated cyclically between 0 and 2 persons/s. At regular intervals, the evacuation speed dropped to $0 \mathrm{~m} / \mathrm{s}$, that is, no one passed through any exit. This means the elevators have just evacuated a group of personnel to the ground, while the next batch of personnel are waiting for elevators or being carried by the elevators.

According to the simulation results, when five SESs were deployed in the station, the sunken shelter + SES evacuation model could evacuate all personnel in $6 \mathrm{~min}$, under an emergency specified in relevant regulations. Therefore, the safe evacuation of the station can be realized by setting up 5 SESs, each of which contains two elevators and two staircases. Although the elevators alone could evacuate all personnel, the evacuation efficiency of the SESs needs to be stabilized by using staircases with elevators: the diversion by staircases promotes the evacuation stability of elevators.

\section{CONCLUSIONS}

This paper proposes a safe evacuation model for the UUPS, which combines the sunken shelter with the SES. The integrated evacuation model reduces the safety threat to the personnel being evacuated from the UUPS, providing a safe and feasible way to evacuate a large crowd. The proposed SES also achieves desirable evacuation effect. Of course, the simulated evacuation process is more ideal than the actual process, which is more complex and changeable. The actual evacuation time of our model could be slighter longer than the simulated time. Despite this, the research results offer a new solution to the safe evacuation from the UUPS.

\section{ACKNOWLEDGMENT}

This work is supported by Chongqing Fundamental and Frontier Research (Grant No.: cstc2017jcyjAX0260), Chongqing Social Career and People's Livelihood Guarantee Science and Technology Innovation Special Program (Grant No.: cstc2016shmszx30017).

\section{REFERENCES}

[1] Zhen, Q. (2019). Development and utilization of urban underground space. IOP Conference Series: Earth and Environmental Science, 242(5): 137-145. https://doi.org/10.1088/1755-1315/242/5/052059

[2] Yin, W.L. (2019). Research on the pattern of urban underground space development and utilization in medium cities. IOP Conference Series: Earth and Environmental Science, 218(1): 315-321. https://doi.org/10.1088/1755-1315/218/1/012111

[3] Khamis, N., Selamat, H., Ismail, F.S., Lutfy, O.F., Haniff, M.F., Nordin, I.N.A.M. (2020). Optimized exit door locations for a safer emergency evacuation using crowd evacuation model and artificial bee colony optimization. 
Chaos, Solitons \& Fractals, 131: 109505. https://doi.org/10.1016/j.chaos.2019.109505

[4] Yue, H., Liu, Q.M., Wu, X.S. (2020). Simulation of pedestrian stampede in pedestrian facilities. Journal of Transportation Systems Engineering and Information Technology, 3: 190-197. https://doi.org/10.16097/j.cnki.1009-6744.2020.03.029

[5] Zlateski, A., Lucesoli, M., Bernardini, G., Ferreira, T.M. (2020). Integrating human behaviour and building vulnerability for the assessment and mitigation of seismic risk in historic centres: Proposal of a holistic human-centred simulation-based approach. International Journal of Disaster Risk Reduction, 43: 101392. https://doi.org/10.1016/j.ijdrr.2019.101392

[6] Liu, H., Chen, H., Hong, R., Liu, H., You, W. (2020). Mapping knowledge structure and research trends of emergency evacuation studies. Safety Science, 121: 348361. https://doi.org/10.1016/j.ssci.2019.09.020

[7] Xu, Z., Wei, W., Jin, W., Xue, Q.R. (2020). Virtual drill for indoor fire evacuations considering occupant physical collisions. Automation in Construction, 109: 102999. https://doi.org/10.1016/j.autcon.2019.102999

[8] Rostami, R., Alaghmandan, M. (2020). Performancebased design in emergency evacuation: From maneuver to simulation in school design. Journal of Building Engineering, 33 : 101598. https://doi.org/10.1016/j.jobe.2020.101598

[9] Zhang, Z., Herrera, N., Tuncer, E., Parr, S., Shapouri, M., Wolshon, B. (2020). Effects of shadow evacuation on megaregion evacuations. Transportation Research Part D: Transport and Environment, 83: 102295. https://doi.org/10.1016/j.trd.2020.102295

[10] Qin, J., Liu, C., Huang, Q. (2020). Simulation on fire emergency evacuation in special subway station based on Pathfinder. Case Studies in Thermal Engineering, 21: 677-684. https://doi.org/10.1016/j.csite.2020.100677

[11] Jin, B., Wang, J., Wang, Y., Gu, Y., Wang, Z. (2020). Temporal and spatial distribution of pedestrians in subway evacuation under node failure by multi-hazards. Safety $\quad$ Science, $\quad$ 127: 469-475. https://doi.org/10.1016/j.ssci.2020.104695

[12] Tsukahara, M., Koshiba, Y., Ohtani, H. (2011).
Effectiveness of downward evacuation in a large-scale subway fire using Fire Dynamics Simulator. Tunnelling and Underground Space Technology, 26(4): 573-581. https://doi.org/10.1016/j.tust.2011.02.002

[13] Haghani, M. (2020). Optimising crowd evacuations: mathematical, architectural and behavioural approaches. Safety Science, 128: 474-480. https://doi.org/10.1016/j.ssci.2020.104745

[14] Alam, M.J., Habib, M.A. (2020). Modeling Traffic Disruptions during Mass Evacuation. Procedia Computer Science, 170: 506-513. https://doi.org/10.1016/j.procs.2020.03.115

[15] Gao, H., Medjdoub, B., Luo, H., Zhong, H., Zhong, B., Sheng, D. (2020). Building evacuation time optimization using constraint-based design approach. Sustainable Cities and Society, 52: 839-844. https://doi.org/10.1016/10.1016/j.scs.2019.101839

[16] Li, Z., Xu, W.T. (2020). Pedestrian evacuation within limited-space buildings based on different exit design schemes. Safety Science, 124: 457-461. https://doi.org/10.1016/j.ssci.2019.104575

[17] Guo, X.M., Yao, B., Li, Z., Zuo, T.C. (2018). Optimization study on high-rise building collaborative evacuation by combined use of stairs with elevators. Fire Safety Science, 1: 53-61. http://dx.chinadoi.cn/10.3969/j.issn.10045309.2018.01. 07.

[18] Hu, W.S., LI, J.Z., LI, Z.L., Cui, Y. (2015). Design of vertical evacuation body for super deep underground public space based on the pathfinder. Journal of Logistical Engineering University, 31(6): 27-32. http://dx.chinadoi.cn/10.3969/j.issn.10000232.2015.05.089.

[19] Nguyen, K.T.Q., Mendis, P., Fernando, S. (2019). Novel modelling approach for evacuation strategies of tall towers-A case study of Lotus Tower. Journal of Building Engineering, 25: 100763. https://dx.doi.org/10.1016/j.jobe.2019.100763

[20] Broere, W. (2016). Urban underground space: Solving the problems of today's cities. Tunnelling and Underground Space Technology, 55: 245-248. https://doi.org/10.1016/j.tust.2015.11.012 